\title{
Role of hypoxia on increased blood pressure in patients with obstructive sleep apnoea
}

\author{
S Okabe, W Hida, Y Kikuchi, O Taguchi, H Ogawa, A Mizusawa, H Miki, K Shirato
}

\begin{abstract}
Background - Cyclical changes in systemic blood pressure occur during apnoeic episodes in patients with obstructive sleep apnoea (OSA). Although several factors including arterial hypoxaemia, intrathoracic pressure changes, and disruption of sleep architecture have been reported to be responsible for these changes in blood pressure, the relative importance of each factor remains unclear. This study assessed the role of hypoxaemia on the increase in blood pressure during apnoeic episodes.
\end{abstract}

Methods - The blood pressure in apnoeic episodes during sleep and the blood pressure response to isocapnic intermittent hypoxia whilst awake were measured in 10 men with OSA. While asleep the blood pressure was measured non-invasively using a Finapres blood pressure monitor with polysomnography. The response of the blood pressure to hypoxia whilst awake was also measured while the subjects intermittently breathed a hypoxic $(5 \%$ or $7 \%$ oxygen) gas mixture. Each hypoxic gas exposure was continued until a nadir arterial oxygen saturation $\left(\mathrm{nSaO}_{2}\right)$ of less than $75 \%$ was reached, or for a period of 100 seconds. The exposure was repeated five times in succession with five interposed breaths of room air in each run.

Results - The mean (SD) increase in blood pressure ( $\triangle \mathrm{MBP})$ during apnoeic episodes was $42 \cdot 1(17 \cdot 3) \mathrm{mm} \mathrm{Hg}$ during rapid eye movement (REM) sleep and 31.9 (12.5) mm Hg during non-REM sleep. The $\triangle M B P$ during apnoeic episodes showed a correlation with the decrease of $\mathrm{nSaO}_{2}$ $\left(\Delta \mathrm{SaO}_{2}\right)\left(r^{2}=0 \cdot 30\right)$. The change in blood pressure in response to intermittent hypoxia whilst awake was cyclical and qualitatively similar to that during apnoeic episodes. Averaged $\triangle \mathrm{MBP}$ at an $\mathrm{SaO}_{2}$ of $7 \%$ and $5 \%$ oxygen was $12.6(5.7)$ and 13.4 (3.6) $\mathrm{mm} \mathrm{Hg}$, respectively, whereas the averaged $\triangle \mathrm{MBP}$ at the same $\Delta \mathrm{SaO}_{2}$ during apnoeic episodes was $38.4(15 \cdot 5)$ and 45.2 (20.5) $\mathrm{mm} \mathrm{Hg}$, respectively.

Conclusions - The blood pressure response to desaturation whilst awake was about one third of that during apnoeic episodes. These results suggest that factors other than hypoxia may play an important part in raising the blood pressure during obstructive sleep apnoea.

(Thorax 1995;50:28-34)

Keywords: hypoxia, blood pressure, obstructive sleep apnoea.
The cardiovascular changes associated with apnoeic episodes in patients with obstructive sleep apnoea (OSA) are characterised by cyclical changes in systemic arterial blood pressure, heart rate, and sympathetic nerve activity. ${ }^{1-7}$ Increased blood pressure, heart rate, and sympathetic nerve activity coincide with termination of apnoeas and a reduction of arterial oxygen saturation $\left(\mathrm{SaO}_{2}\right)$. Several features including arterial hypoxaemia, ${ }^{38-12}$ intrathoracic pressure changes, ${ }^{13-15}$ carbon dioxide retention and acidosis, ${ }^{16}$ and disruption of sleep architecture ${ }^{1718}$ have been reported to cause these events. Amongst them, arterial hypoxaemia has been suggested to play a major part in increasing blood pressure during apnoeic episodes as systolic blood pressure is known to be correlated with arterial oxygen desaturation during sleep apnoea and blood pressure rises are blunted by oxygen administration. ${ }^{36}$ In contrast, Ringler et al have shown that, in the absence of respiratory and sleep disruptions, hypoxaemia is not associated with increased blood pressure during sleep in patients with OSA. ${ }^{17}$ Similarly, Davies et al have shown in normal subjects that, during non-rapid eye movement (non-REM) sleep, transient arousal evokes a rise in blood pressure large enough to explain most of the postapnoeic increase seen during obstructive sleep apnoea. ${ }^{18}$ The reasons for these contradictory findings remain unclear. However, the importance of hypoxaemia has been postulated mostly by findings obtained during non-normal sleep, such as while awake or during anaesthesia, ${ }^{8-12}$ whereas the importance of arousal has been evaluated during sleep. ${ }^{1718}$ There have been no reports in which increases in blood pressure have been compared during sleep apnoea and whilst awake in the same subjects. To assess the role of hypoxaemia on increased blood pressure in apnoea we have measured the blood pressure response to intermittent hypoxia while awake and compared it with the increase in blood pressure seen during apnoeic episodes while asleep in patients with OSA.

\section{Methods}

SUBJECTS

Ten newly diagnosed patients with OSA, in a clinically stable condition, were studied. Two patients had received medication for hypertension for five and eight years, and the drugs were withheld from them for one week before the studies. All patients were habitual snorers and complained of excessive daytime sleepiness. No patients had been treated by nasal continuous positive airway pressure (CPAP) 
or by any other treatment for sleep apnoea. Ventilatory response to progressive isocapnic hypoxia was measured by the modified RebuckCampbell method in which end tidal carbon dioxide was kept at the value of resting control breathing while awake. The ventilatory responses were measured with a circuit similar to that reported previously. ${ }^{19}$ The ventilatory slope to hypoxia $\left(\Delta \dot{\mathrm{VE}} / \Delta \mathrm{SaO}_{2}\right)$ was determined from the regression line. A control overnight sleep study was performed in the supine position in a dark, quiet room using standard polysomnographic equipment including electroencephalography (EEG; C4/A1, C3/ A2), electrooculography (EOG), submental electromyography (EMG) with surface electrodes, airflow at nose and mouth obtained with two thermistors, inductive plethysmography (Respitrace; Ambulatory Monitoring Inc, Ardsley, New York, USA), and $\mathrm{SaO}_{2}$ with a finger pulse oximeter (Biox 3700; Ohmeda, Boulder, Colorado, USA). All variables were recorded on an eight channel thermal chart recorder (Model 360; NEC San-ei, Tokyo, Japan) and a data recorder (A-109; Sony, Tokyo, Japan). Apnoea was defined as cessation of airflow lasting more than $10 \mathrm{sec}-$ onds and the apnoea index was calculated according to the definition of Guilleminault and associates. ${ }^{1}$ Hypopnoea was excluded in the computation of the apnoea index. Obstructive apnoea was classified using the Respitrace and airflow signals.

Written informed consent to the protocol which had received prior approval of the Human Research Committee of our institution was obtained from each subject before the start of the study.

RESPONSE OF BLOOD PRESSURE TO HYPOXIA WHILST AWAKE

The response of blood pressure to intermittent hypoxia whilst awake was measured in a quiet room after fasting for two hours and at least eight hours after any coffee or tea. The subjects were placed in the supine position and wore a noseclip and breathed through a mouthpiece connected to an open circuit. The circuit contained a low dead space two way valve (Model 1900; Hans Rudolph, Kansas City, Missouri, USA) pierced to allow continuous sampling of inspired and expired gas. The inspiratory limb could be switched from room air to a large reservoir of premixed gas of low fractional oxygen concentration without alerting the subject. Two different concentrations of oxygen (7\% and $5 \%$ in nitrogen) were used. A supplemental pressurised source of carbon dioxide was attached to the outflow of the reservoir bag to control its fractional concentration. The fractional concentrations of expired carbon dioxide and oxygen were monitored with a mass spectrometer (WSMR-1400; Westron, Chiba, Japan). $\mathrm{SaO}_{2}$ was measured continuously at the right digital finger with a pulse oximeter. Arterial blood pressure was measured continuously and non-invasively using a blood pressure monitor (Finapres Model 2300; Ohmeda, Englewood, Colorado, USA). Recordings were made from a cuff positioned on the second phalanx of the middle finger of the left hand, which was kept at a similar hydrostatic level to the heart. To avoid the risk of falling asleep during the study an operator encouraged the subjects to keep their eyes open. All variables were recorded on a 12 channel thermal chart recorder (Recti-horiz-8k; NEC San-ei, Tokyo, Japan).

The protocol for examining the effects of intermittent hypoxia on blood pressure was as follows: (1) control periods of room air breathing for 10 minutes; (2) abrupt step decrease in fractional oxygen concentration of inspiratory gas; (3) low fractional oxygen concentration gas breathing until $\mathrm{SaO}_{2}$ reached less than $75 \%$ or for a period of 100 seconds, with a constant end tidal carbon dioxide equal to the levels when breathing room air; (4) abrupt step increase in fractional oxygen concentration of inspiratory gas to room air; (5) room air breathing for five breaths; (6) return to procedure (2). The procedures (2) to (5) were repeated five times for each run. During the test, subjects were not restricted in their breathing. Changes in blood pressure during hypoxia while awake were evaluated from the difference between blood pressure during control breathing and the peak value of blood pressure induced by each hypoxic gas exposure. Mean blood pressure, equivalent to one third systolic blood pressure plus two thirds diastolic blood pressure, was used for statistical analysis of results. The decrease in $\mathrm{SaO}_{2}$ from the value of the control period to the nadir of $\mathrm{SaO}_{2}\left(\mathrm{nSaO}_{2}\right)$ in each hypoxic exposure was used as the $\mathrm{SaO}_{2}$ decrease during hypoxia whilst awake.

MEASUREMENT OF BLOOD PRESSURE DURING

APNOEIC EPISODES WHILST ASLEEP

Overnight blood pressure was measured in the same way as the control polysomnographic examination, which included EEG, EOG, submental EMG airflow at nose and mouth, inductive plethysmography, and $\mathrm{SaO}_{2}$ in a dark, quiet room. This measurement was performed on a different day but within one week of those made whilst awake. Blood pressure was measured continuously and non-invasively using a Finapres monitor in the same way as described above. All parameters were recorded throughout the night. The values during the first period of stage 2 non-REM sleep and the first period of REM sleep were assessed for data analysis. The change in blood pressure was evaluated from the difference between the blood pressure just before sleep and the peak blood pressure value induced by each apnoeic episode. The change in $\mathrm{SaO}_{2}$ was evaluated from the difference between the $\mathrm{SaO}_{2}$ just before sleep and the nadir $\mathrm{SaO}_{2}$ in each apnoeic episode. Mean blood pressure and $\mathrm{SaO}_{2}$ just before sleep were not significantly different from those during control breathing whilst awake. Sleep stage was determined according to standard criteria. $^{20}$

\section{DATA ANALYSIS}

Comparisons between the two groups were performed by paired $t$ tests. Linear regression 
Table 1 Clinical features of patients with obstructive sleep apnoea

\begin{tabular}{|c|c|c|c|c|c|c|c|c|}
\hline $\begin{array}{l}\text { Subject } \\
\text { no. }\end{array}$ & $\begin{array}{l}\text { Age } \\
(y r)\end{array}$ & $\begin{array}{c}B M I \\
\left(\mathrm{~kg} / \mathrm{m}^{2}\right)\end{array}$ & $\begin{array}{c}\% V C \\
\text { (\%pred) }\end{array}$ & $\begin{array}{c}F E V_{l} / V C \\
(\%)\end{array}$ & $\begin{array}{c}\mathrm{PaO}_{2} \\
(\mathrm{~mm} \mathrm{Hg})\end{array}$ & $\begin{array}{c}\mathrm{PaCO}_{2} \\
(\mathrm{~mm} \mathrm{Hg})\end{array}$ & $\begin{array}{c}\Delta \dot{V E} / \Delta \mathrm{SaO}_{2} \\
\left(\mathrm{l} / \mathrm{min} / \% \mathrm{SaO}_{2}\right)\end{array}$ & $\begin{array}{c}A I \\
\text { (lhour) }\end{array}$ \\
\hline 1 & 47 & $26 \cdot 0$ & 103 & $82 \cdot 6$ & 83 & $42 \cdot 6$ & $0 \cdot 21$ & $52 \cdot 9$ \\
\hline 2 & 38 & $29 \cdot 0$ & 97 & $83 \cdot 1$ & 83 & 44.5 & 0.94 & $64 \cdot 9$ \\
\hline 3 & 44 & 30.5 & 116 & $89 \cdot 3$ & 73 & $42 \cdot 8$ & 0.74 & $45 \cdot 2$ \\
\hline 4 & 61 & $29 \cdot 0$ & 102 & 83.5 & 76 & $39 \cdot 4$ & 0.84 & $25 \cdot 1$ \\
\hline 5 & 34 & $26 \cdot 5$ & 120 & $82 \cdot 8$ & 91 & 41.8 & 0.50 & $57 \cdot 7$ \\
\hline 6 & 59 & $24 \cdot 3$ & 128 & 82.9 & 69 & 49.0 & 0.23 & $42 \cdot 7$ \\
\hline 7 & 49 & 22.9 & 102 & $80 \cdot 9$ & 80 & $44 \cdot 2$ & 0.61 & $57 \cdot 3$ \\
\hline 8 & 29 & $33 \cdot 8$ & 106 & $84 \cdot 6$ & 80 & $45 \cdot 2$ & 0.73 & $73 \cdot 8$ \\
\hline 9 & 40 & 26.9 & 107 & $81 \cdot 0$ & 76 & $45 \cdot 3$ & $0 \cdot 32$ & $49 \cdot 3$ \\
\hline 10 & 58 & $31 \cdot 2$ & 138 & 79.9 & 71 & $40 \cdot 1$ & $0 \cdot 22$ & $60 \cdot 1$ \\
\hline Mean & $45 \cdot 9$ & $28 \cdot 0$ & 112 & $83 \cdot 1$ & $78 \cdot 2$ & $43 \cdot 5$ & 0.53 & $52 \cdot 9$ \\
\hline SD & $11 \cdot 0$ & $3 \cdot 3$ & $13 \cdot 2$ & $2 \cdot 60$ & $6 \cdot 6$ & $2 \cdot 8$ & $0 \cdot 28$ & $13 \cdot 4$ \\
\hline
\end{tabular}

$\mathrm{BMI}=$ body mass index; $\% \mathrm{VC}=$ percentage of vital capacity to predicted value; $\mathrm{FEV}_{1} / \mathrm{VC}=$ forced expiratory volume in one second/vital capacity; $\Delta \mathrm{VE} / \Delta \mathrm{SaO}_{2}=$ ventilatory response to hypoxia whilst awake; $\mathrm{AI}=$ apnoea index, number of apnoeas per hour of sleep.

analysis was performed by the least squares method. Data are expressed as means (SD). Significance was accepted at $\mathrm{p}<0 \cdot 05$.

\section{Results}

The anthropometric data, spirometric data, arterial blood gas tensions, and hypoxic ventilatory response whilst awake and apnoeic indices during polysomnography are shown in table 1. Their hypoxic ventilatory response ranged from 0.21 to $0.94 \mathrm{l} / \mathrm{min} / \% \mathrm{SaO}_{2}$, and their apnoeic indices from $25 \cdot 1$ to 73.8 episodes/hour.

The response of blood pressure to $7 \%$ oxygen was analysed in all patients but the response to $5 \%$ oxygen was analysed in only eight of the 10 patients. The two other patients complained of moderate to severe dyspnoea or anxiety when inhaling $5 \%$ oxygen. Figure $1 \mathrm{~A}$ shows an example of the blood pressure response to intermittent exposure to $5 \%$ oxygen in one patient. During each period of hypoxia the blood pressure increased gradually with a decrease of $\mathrm{SaO}_{2}$, and reached a peak value during the period breathing room air that followed. A nadir $\mathrm{SaO}_{2}$ always followed the termination of each hypoxic exposure. The time delay between the end of hypoxic exposure and the $\mathrm{nSaO}_{2}$ was approximately 20 seconds.

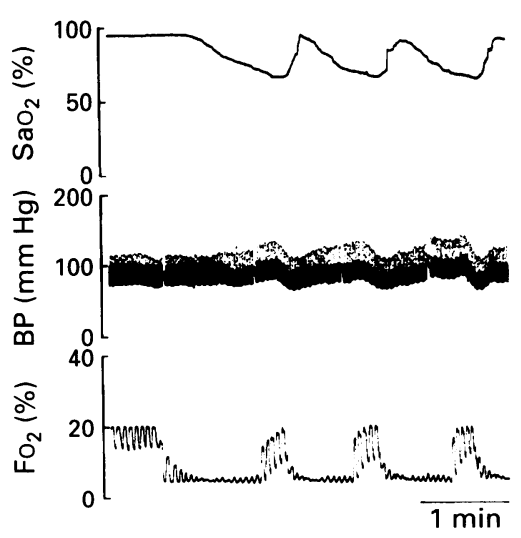

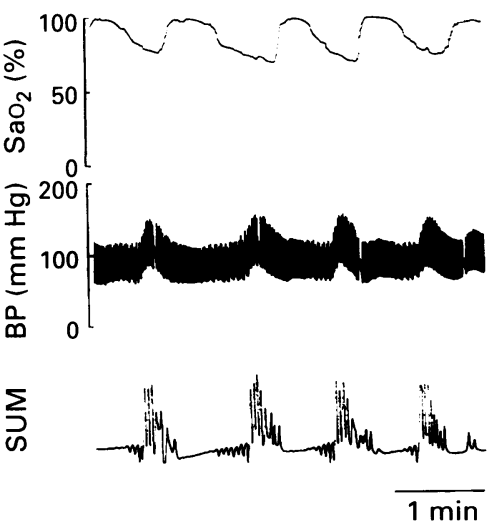

Figure 1 Systemic blood pressure response to $(A)$ intermittent hypoxia and $(B)$ part of a polysomnographic recording including systemic blood pressure during non-REM sleep in one patient: $\mathrm{SaO}_{2}=$ arterial oxygen saturation; $\mathrm{BP}=$ blood pressure measured with Finapres; $\mathrm{FO}_{2}=$ fractional concentration of oxygen; $S U M=$ ribcage plus abdominal motions in inductive plethysmography.
Averaged $\mathrm{nSaO}_{2}$ and the duration of each hypoxic exposure are summarised in table 2. The $\mathrm{nSaO}_{2}$ did not reach $75 \%$ with the $7 \%$ oxygen mixture within 100 seconds in two patients. At $5 \%$ oxygen exposure the $\mathrm{nSaO}_{2}$ was significantly lower than at $7 \%$ oxygen and the duration of each hypoxic exposure to $5 \%$ oxygen was significantly shorter than with $7 \%$ oxygen in the eight patients who experienced both concentrations. Thus, the rate of decrease of $\mathrm{SaO}_{2}$ during $5 \%$ oxygen exposure was faster than that during $7 \%$ oxygen breathing. The blood pressure during control conditions and the averaged value of peak blood pressure during the hypoxic exposure run are shown in table 3. Both systolic and diastolic blood pressure were raised from the control value by hypoxic exposure. The increase in mean blood pressure $(\triangle \mathrm{MBP})$ per decrease in $\mathrm{SaO}_{2}\left(\Delta \mathrm{SaO}_{2}\right)$ was used as an index of the pressure responsiveness to a given change in $\mathrm{SaO}_{2}$ while awake. The averaged $\Delta \mathrm{MBP} / \Delta \mathrm{SaO}_{2}$ of each patient ranged from 0.33 to 0.87 (mean 0.53 ) and from 0.33 to 0.64 (mean 0.48 ) $\mathrm{mm} \mathrm{Hg}$ / $\% \mathrm{SaO}_{2}$ for the $7 \%$ and $5 \%$ oxygen inhalations, respectively. There was no significant difference between the pressure responsiveness to the two low oxygen mixtures. Averaged $\Delta \mathrm{MBP} / \Delta \mathrm{SaO}_{2}$ during $7 \%$ oxygen inhalation was significantly related to the ventilatory slope to hypoxia $(r=$ $0 \cdot 67$ ) (fig 2).

Because of technical problems the blood pressure could not be measured during REM sleep in two patients. The number of apnoeic episodes, mean $\mathrm{nSaO}_{2}$, and mean apnoea duration during the first periods of stage 2 nonREM sleep and REM sleep are shown in table 2. During REM sleep $\mathrm{nSaO}_{2}$ decreased further and the apnoea duration was longer than during non-REM sleep. Figure 1B shows a part of the polysomnographic recording of the blood pressure during non-REM sleep in one patient. During one apnoeic phase blood pressure started to increase in the later period with a decrease in $\mathrm{SaO}_{2}$ and reached a peak value during the room air breathing period that followed. The $\mathrm{nSaO}_{2}$ induced by each apnoea followed the end of the apnoea by approximately 20 seconds. The averaged peak values of systolic and diastolic blood pressure during non-REM sleep and during REM sleep are shown in table 3 and both were significantly increased compared with the values before sleep (con- 
Table 2 Nadir of arterial oxygen saturation ( $n \mathrm{SaO}_{2}$ ) and duration of hypoxia or apnoea in hypoxic exposure while awake and in apnoeic episodes during sleep

\begin{tabular}{|c|c|c|c|c|c|c|c|c|c|c|}
\hline \multirow{3}{*}{$\begin{array}{l}\text { Subject } \\
\text { no. }\end{array}$} & \multicolumn{4}{|l|}{ Awake } & \multicolumn{6}{|l|}{ Asleep } \\
\hline & \multicolumn{2}{|l|}{$n \mathrm{SaO}_{2}$} & \multicolumn{2}{|c|}{ Duration of hypoxia } & \multicolumn{2}{|c|}{ No. of episodes } & \multicolumn{2}{|l|}{$n \mathrm{SaO}_{2}$} & \multicolumn{2}{|c|}{ Duration of apnoea } \\
\hline & $\begin{array}{l}7 \% \mathrm{O}_{2} \\
(\%)\end{array}$ & $\begin{array}{l}5 \% \mathrm{O}_{2} \\
\text { (\%) }\end{array}$ & $\begin{array}{l}7 \% \mathrm{O}_{2} \\
\text { (seconds) }\end{array}$ & $\begin{array}{l}5 \% \mathrm{O}_{2} \\
\text { (seconds) }\end{array}$ & Non-REM & $R E M$ & $\begin{array}{l}\text { Non-REM } \\
(\%)\end{array}$ & $\begin{array}{l}R E M \\
(\%)\end{array}$ & $\begin{array}{l}\text { Non-REM } \\
\text { (seconds) }\end{array}$ & $\begin{array}{l}R E M \\
\text { (seconds) }\end{array}$ \\
\hline $\begin{array}{r}1 \\
2 \\
3 \\
4 \\
5 \\
6 \\
7 \\
8 \\
9 \\
10\end{array}$ & $\begin{array}{l}72 \cdot 6 \\
73 \cdot 0 \\
74 \cdot 0 \\
69 \cdot 8 \\
82 \cdot 3 \\
72 \cdot 6 \\
75 \cdot 6 \\
71 \cdot 2 \\
70 \cdot 6 \\
71 \cdot 8\end{array}$ & $\begin{array}{l}66 \cdot 2 \\
68 \cdot 4 \\
- \\
-75 \cdot 4 \\
71 \cdot 8 \\
67 \cdot 0 \\
68 \cdot 0 \\
65 \cdot 2 \\
66 \cdot 2\end{array}$ & $\begin{array}{l}70 \cdot 0 \\
59 \cdot 7 \\
58 \cdot 8 \\
65 \cdot 3 \\
102 \\
54 \cdot 6 \\
104 \\
60 \cdot 4 \\
54 \cdot 6 \\
56 \cdot 2\end{array}$ & $\begin{array}{l}53 \cdot 8 \\
44 \cdot 0 \\
- \\
\overline{96} \\
56 \cdot 6 \\
50 \cdot 7 \\
43 \cdot 8 \\
43 \cdot 2 \\
50 \cdot 8\end{array}$ & $\begin{array}{r}51 \\
125 \\
54 \\
62 \\
73 \\
81 \\
27 \\
75 \\
61 \\
73\end{array}$ & $\begin{array}{l}18 \\
23 \\
25 \\
23 \\
16 \\
18 \\
17 \\
18\end{array}$ & $\begin{array}{l}87 \cdot 2 \\
82 \cdot 2 \\
81 \cdot 6 \\
87 \cdot 9 \\
84 \cdot 3 \\
81 \cdot 9 \\
87 \cdot 1 \\
66 \cdot 4 \\
75 \cdot 3 \\
76 \cdot 3\end{array}$ & $\begin{array}{l}83 \cdot 9 \\
64 \cdot 7 \\
\overline{74} \cdot 9 \\
75 \cdot 2 \\
76 \cdot 5 \\
\overline{46 \cdot 6} \\
70 \cdot 5 \\
73 \cdot 2\end{array}$ & $\begin{array}{l}31 \cdot 1 \\
35 \cdot 7 \\
26 \cdot 2 \\
37 \cdot 2 \\
40 \cdot 7 \\
49 \cdot 8 \\
28 \cdot 4 \\
29 \cdot 2 \\
37 \cdot 5 \\
49 \cdot 6\end{array}$ & $\begin{array}{l}45 \cdot 3 \\
55 \cdot 2 \\
- \\
52 \cdot 9 \\
54 \cdot 6 \\
63 \cdot 3 \\
-72 \cdot 9 \\
44 \cdot 5 \\
66 \cdot 4\end{array}$ \\
\hline $\begin{array}{l}\text { Mean } \\
\text { SD }\end{array}$ & $\begin{array}{c}73 \cdot 4 \\
3.47\end{array}$ & $\begin{array}{c}68 \cdot 5 \\
3 \cdot 43\end{array}$ & $\begin{array}{l}68 \cdot 6 \\
18 \cdot 8\end{array}$ & $\begin{array}{l}55 \cdot 0 \\
17 \cdot 6\end{array}$ & $\begin{array}{l}68 \cdot 2 \\
25 \cdot 3\end{array}$ & $\begin{array}{r}19 \cdot 8 \\
3 \cdot 4\end{array}$ & $\begin{array}{r}81 \cdot 0 \\
6 \cdot 7\end{array}$ & $\begin{array}{l}70 \cdot 7 \\
11 \cdot 1\end{array}$ & $\begin{array}{r}36 \cdot 5 \\
8 \cdot 3\end{array}$ & $\begin{array}{r}53 \cdot 1 \\
8 \cdot 7\end{array}$ \\
\hline
\end{tabular}

Values of $\mathrm{nSaO}_{2}$ and duration of hypoxia while awake are means for five hypoxic exposures. Values of $\mathrm{nSaO}{ }_{2}$ and duration of apnoea during sleep are means for each apnoeic episodes.

No. of episodes $=$ evaluated numbers of apnoeic episodes.

Table 3 Systolic/diastolic blood pressure in hypoxic exposure whilst awake and in apnoeic episodes during sleep

\begin{tabular}{|c|c|c|c|c|c|c|c|}
\hline \multirow{3}{*}{$\begin{array}{l}\text { Subject } \\
\text { no. }\end{array}$} & \multicolumn{4}{|l|}{ Awake } & \multicolumn{3}{|l|}{ Asleep } \\
\hline & \multicolumn{2}{|l|}{$7 \% \mathrm{O}_{2}$} & \multicolumn{2}{|l|}{$5 \% \mathrm{O}_{2}$} & \multirow[b]{2}{*}{$\begin{array}{l}\text { Control } \\
(\mathrm{mm} \mathrm{Hg})\end{array}$} & \multirow[b]{2}{*}{$\begin{array}{l}\text { Non-REM } \\
(\mathrm{mm} \mathrm{Hg})\end{array}$} & \multirow[b]{2}{*}{$\begin{array}{l}R E M \\
(m m H g)\end{array}$} \\
\hline & $\begin{array}{l}\text { Control } \\
(m m \mathrm{Hg})\end{array}$ & $\begin{array}{l}\text { Hypoxia } \\
(m m \mathrm{Hg})\end{array}$ & $\begin{array}{l}\text { Control } \\
(m m \mathrm{Hg})\end{array}$ & $\begin{array}{l}\text { Hypoxia } \\
(\mathrm{mm} \mathrm{Hg})\end{array}$ & & & \\
\hline $\begin{array}{r}1 \\
2 \\
3 \\
4 \\
5 \\
6 \\
7 \\
7 \\
8 \\
9 \\
10\end{array}$ & $\begin{array}{l}110 / 48 \\
120 / 83 \\
109 / 78 \\
143 / 78 \\
173 / 109 \\
116 / 73 \\
135 / 85 \\
120 / 68 \\
105 / 65 \\
110 / 68\end{array}$ & $\begin{array}{l}131 / 58 \\
148 / 93 \\
123 / 83 \\
175 / 94 \\
186 / 111 \\
138 / 79 \\
152 / 94 \\
153 / 85 \\
124 / 75 \\
124 / 73\end{array}$ & $\begin{array}{l}130 / 54 \\
111 / 72 \\
- \\
156 / 102 \\
112 / 73 \\
137 / 84 \\
123 / 65 \\
107 / 63 \\
111 / 67\end{array}$ & $\begin{array}{l}158 / 59 \\
136 / 84 \\
- \\
-172 / 106 \\
137 / 79 \\
163 / 99 \\
154 / 76 \\
126 / 73 \\
128 / 73\end{array}$ & $\begin{array}{r}118 / 64 \\
106 / 76 \\
90 / 55 \\
152 / 79 \\
118 / 72 \\
115 / 74 \\
130 / 70 \\
120 / 55 \\
116 / 69 \\
102 / 74\end{array}$ & $\begin{array}{l}167 / 92 \\
134 / 59 \\
120 / 66 \\
216 / 111 \\
155 / 99 \\
153 / 87 \\
194 / 114 \\
193 / 95 \\
144 / 86 \\
147 / 94\end{array}$ & $\begin{array}{l}168 / 91 \\
152 / 105 \\
-235 / 112 \\
173 / 109 \\
168 / 94 \\
-214 / 129 \\
149 / 89 \\
163 / 102\end{array}$ \\
\hline $\begin{array}{l}\text { Mean } \\
\text { SD }\end{array}$ & $\begin{array}{l}124 / 76 \\
21 \cdot 0 / 15 \cdot 9\end{array}$ & $\begin{array}{l}145 / 85 \\
21 \cdot 9 / 14 \cdot 6\end{array}$ & $\begin{array}{l}123 / 73 \\
16 \cdot 9 / 14 \cdot 7\end{array}$ & $\begin{array}{l}147 / 81 \\
17 \cdot 2 / 15 \cdot 1\end{array}$ & $\begin{array}{l}107 / 69 \\
35 \cdot 9 / 8 \cdot 3\end{array}$ & $\begin{array}{l}162 / 90 \\
30 \cdot 1 / 17 \cdot 3\end{array}$ & $\begin{array}{l}178 / 104 \\
30 \cdot 5 / 13 \cdot 1\end{array}$ \\
\hline
\end{tabular}

Control values are blood pressure during resting breathing in supine position just before each hypoxic exposure (awake) and just before sleep (asleep). Values of hypoxia are means for five hypoxic exposures and values of non-REM and REM are means for all analysed apnoeic episodes.

trol). Averaged $\triangle \mathrm{MBP}$ during non-REM sleep and REM sleep were $31.9(12.5)$ and 42.1 $(17 \cdot 3) \mathrm{mm} \mathrm{Hg}$, respectively. $\triangle \mathrm{MBP}$ during REM sleep was significantly greater than that during non-REM sleep.

The relation between $\Delta \mathrm{SaO}_{2}$ and $\triangle \mathrm{MBP}$ in each apnoeic episode during non-REM and REM sleep is shown in fig 3 and did not differ between the two sleep stages. A significant but poor correlation was observed in all patients between $\Delta \mathrm{SaO}_{2}$ and $\triangle \mathrm{MBP}$. The mean value of

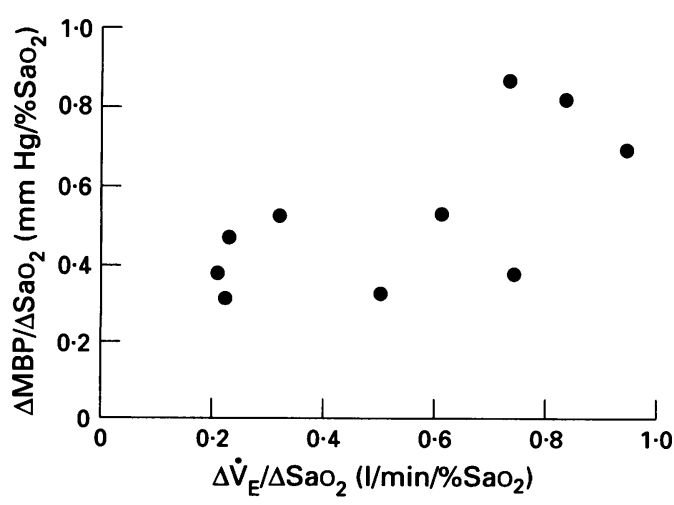

Figure 2 Relationships between the ventilatory slope to hypoxia and the ratio of the increase of mean blood pressure to the decrease in arterial oxygen saturation ( $\left.\triangle \mathrm{MBP} / \triangle \mathrm{SaO}_{2}\right)$ during $7 \%$ oxygen inhalation. the square of the correlation coefficient $\left(r^{2}\right)$ for this was $0.30(0 \cdot 15)$. The linear regression line of the blood pressure response slope was $0 \cdot 79$ $(0.44) \mathrm{mm} \mathrm{Hg} / \% \mathrm{SaO}_{2}$. The $y$ axis intercepts for $\Delta \mathrm{SaO}_{2}=0 \%$ given by the constants in the linear regression line were always positive and were $21.7(10.4) \mathrm{mm} \mathrm{Hg}$ (range $7 \cdot 7-42 \mathrm{~mm} \mathrm{Hg}$ ). This intercept value could account for $67 \cdot 0$ $(15 \cdot 8) \%$ and $54 \cdot 1(18.5) \%$ of the averaged $\triangle M B P$ during non-REM and REM sleep, respectively.

Figure 4 shows the $\triangle \mathrm{MBP}$ at the $\mathrm{nSaO}_{2}$ of $7 \%$ and $5 \%$ oxygen inhalation and the equivalent $\triangle \mathrm{MBP}$, calculated from the regression equation, at the same $\Delta \mathrm{SaO}_{2}$ during apnoeic episodes. The values of $\triangle \mathrm{MBP}$ during hypoxia while awake of $12.6(5.7) \mathrm{mm} \mathrm{Hg}$ with $7 \%$ oxygen inhalation and $13.4(3.6) \mathrm{mm} \mathrm{Hg}$ with $5 \%$ oxygen were significantly smaller than during apnoeic episodes $(38.4(15.5) \mathrm{mm} \mathrm{Hg}$ with $7 \%$ oxygen and $45 \cdot 2(20.5) \mathrm{mm} \mathrm{Hg}$ with $5 \%$ oxygen). Both $\triangle \mathrm{MBP}$ values during hypoxia whilst awake were approximately one third of those during the apnoeic episodes.

\section{Discussion}

We have shown a cyclical change in blood pressure associated with hypoxaemia during repeated intermittent hypoxic exposure whilst awake in patients with OSA. Although the 


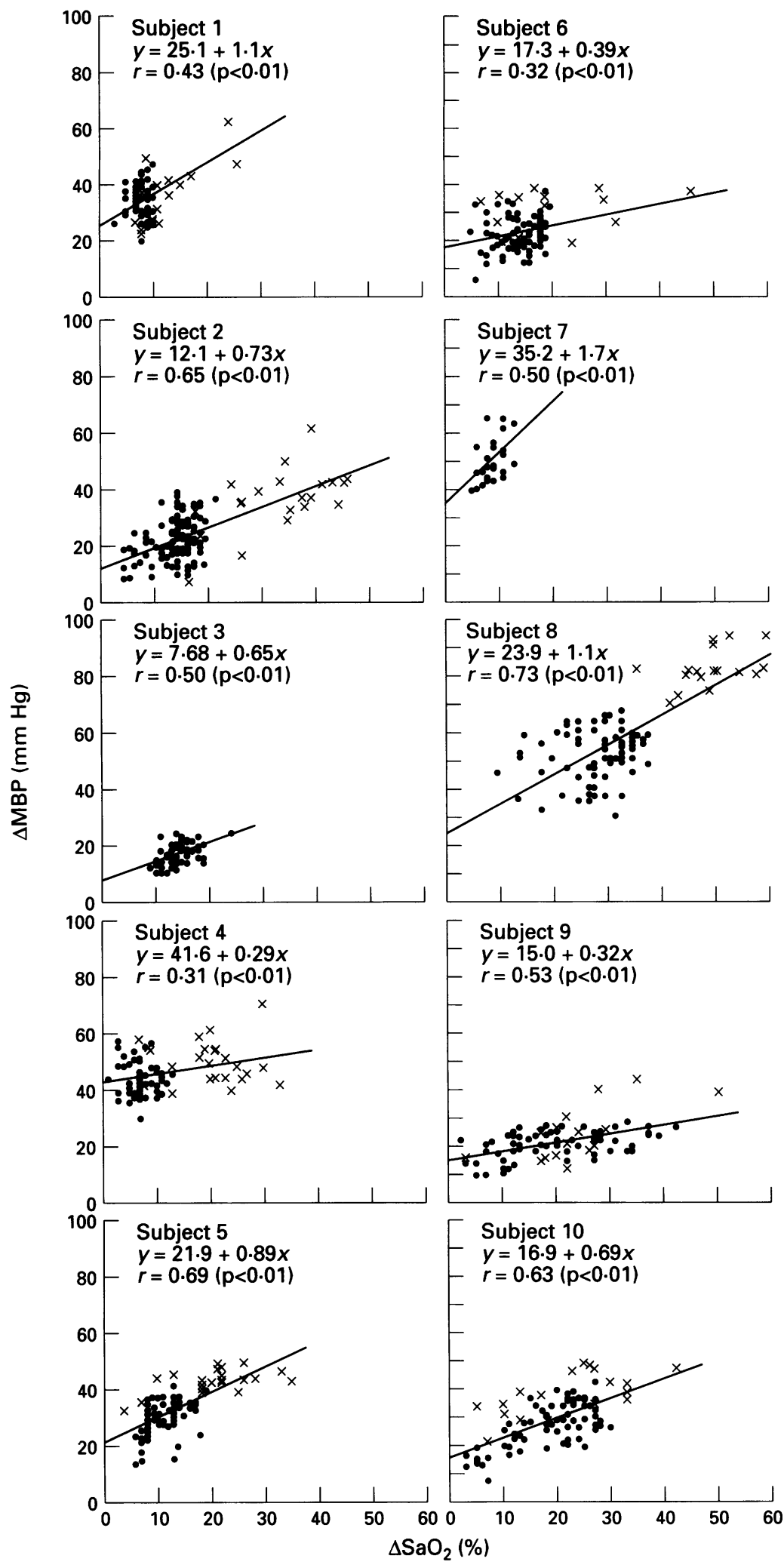

Figure 3 Relationships between the decrease of arterial oxygen saturation $\left(\triangle \mathrm{SaO}_{2}\right)$ and the increases of mean blood pressure $(\triangle M B P)$ in each apnoeic episode during non-REM sleep (O) and REM sleep (x). hypoxic gas inhalations while awake were about one third of those at the same level of $\mathrm{SaO}_{2}$ decrease during apnoeic episodes.

Continuous recording of blood pressure during both hypoxic exposure whilst awake and asleep was performed using the Finapres device, which depends on a pneumatic servocontrolled cuff inflated to keep the infrared absorption of the finger constant by correcting the photoplethysmogram. Blood pressure readings obtained with this technique correlate well with intra-arterial measurements from the radial artery at rest and during experimentally induced changes in blood pressure. ${ }^{21}$ This method seems to have less influence on sleep architecture and blood pressure change than invasive cannulation techniques.

In making the assumption that the increase in blood pressure during intermittent hypoxia whilst awake represents the changes induced primarily by hypoxia during apnoea, one has to consider whether the ventilation of patients with OSA was increased by the intermittent periods of hypoxaemia. Since the cardiovascular effects of hypoxia during spontaneous breathing were different from those during artificial constant ventilation in animal experiments, ${ }^{22}$ the increase in ventilation in itself might influence the blood pressure response to hypoxia. In humans, however, it has been shown that blood pressure does not change significantly during isocapnic hyperventilation. ${ }^{16}$ The increasing ventilation observed during intermittent hypoxia was therefore unlikely to have changed the blood pressure directly. Secondly, the differences in the rate of fall of $\mathrm{SaO}_{2}$ in hypoxic exposure whilst awake and in apnoeic episodes might influence the blood pressure response to hypoxia. There was, however, no significant difference between the blood pressure increase during either $5 \%$ or $7 \%$ oxygen inhalation, although the rate of fall of $\mathrm{SaO}_{2}$ during $5 \%$ oxygen inhalation was more rapid than with $7 \%$ oxygen. There is also the possibility of a different hypoxic blood pressure response whilst awake and during sleep. However, the cardiovascular response to hypoxia does not differ significantly during wakefulness and sleep, ${ }^{23}$ so the change of state from sleep to awake has little effect on the hypoxic blood pressure response. The hypoxic blood pressure response at a fixed lung volume as with obstructive apnoea and that in non-obstructed breathing may not be the same. We have previously examined and compared the blood pressure responses to intermittent hypoxia and to repetitive airways obstruction in anaesthetised $\operatorname{dogs}^{8}$ and found that the relation between the decrease in $\mathrm{SaO}_{2}$ and the increase in blood pressure was similar during intermittent hypoxia and during repetitive airways obstruction. This suggests that the influence of airways obstruction is small. Finally, the degree of cortical awareness including dyspnoea might influence the blood pressure response to hypoxia in hypoxic exposure while awake, despite our omission from the data analysis of the two patients who complained of severe to moderate dyspnoea during hypoxic response. We cannot change in blood pressure due to intermitte hypoxic exposure was qualitatively similar to that during apnoeic episodes, the extent of the blood pressure increase at a given change in $\mathrm{SaO}_{2}$ during hypoxic exposure whilst awake was significantly lower than that during apnoea. The blood pressure increases at $\mathrm{nSaO}_{2}$ of 

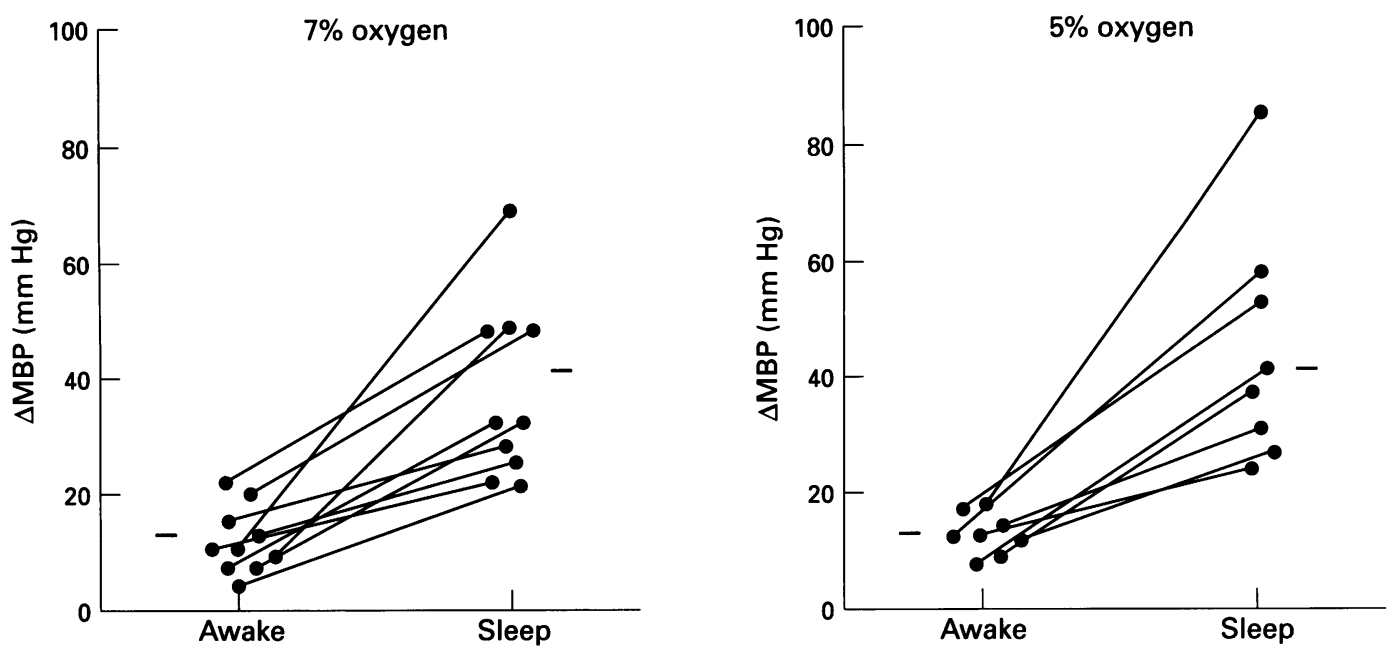

Figure 4 Mean increase in blood pressure ( $\triangle M B P$ ) at nadir $\mathrm{SaO}_{2}$ during $7 \%$ and $5 \%$ oxygen inhalation and interpolated $\triangle M B P$ at the same desaturation during apnoeic episodes. Values of the same patients are connected.

ignore the possibility that cortical awareness enhances the hypoxic blood pressure response during hypoxia whilst awake.

There are several reports ${ }^{38101718}$ of the role of hypoxia on increased blood pressure during sleep apnoeic episodes, but the results are contradictory. Schroeder et al reported that oxygen supplementation blunted the blood pressure increase during apnoea in patients with sleep apnoea. ${ }^{3}$ It has also been reported that periodic hypertension produced by repetitive apnoeas is diminished by oxygen supplementation in normal subjects ${ }^{10}$ and in anaesthetised dogs. ${ }^{8}$ These reports do not conflict with the results of our study. In our patients with OSA the blood pressure was significantly increased during intermittent hypoxia whilst awake, although this increase was significantly less than that during sleep apnoeic episodes. On the other hand, Ringler and coworkers showed that postapnoeic increases in blood pressure were preserved even after amelioration of hypoxaemia during sleep in patients with OSA, and that hypoxaemia without apnoea was not associated with changes in blood pressure during sleep. ${ }^{17}$ Davies et al reported that transient arousal alone caused blood pressure to rise during sleep in normal humans. ${ }^{18}$ Our results agree with these reports, suggesting that non-hypoxic factors may play an important part in increasing blood pressure during sleep apnoea.

A previous report and this study have both shown a significant correlation of the ventilatory response and the pressure response to hypoxia, ${ }^{9}$ which suggests that ventilatory and pressure responses to hypoxia are at least partially modulated by a common mechanism. Experiments in animals suggest that chemoreceptor stimulation by hypoxaemia can raise blood pressure by increasing the total peripheral resistance and the inotropic response of the myocardium. ${ }^{24} 25$ In humans Lugliani et al reported that blood pressure decreased significantly during hypoxia in patients with bilaterally resected carotid bodies, whereas it was maintained or increased in normal subjects. ${ }^{26}$ Schroeder et al reported that blood pressure increases did not occur in two OSA patients with Shy-Drager autonomic dysfunction, ${ }^{3}$ sug- gesting that the hypoxia-induced rise in blood pressure is modulated by chemoreceptors and the autonomic nervous system. On the other hand, the local vascular effect of hypoxia is inhibitory and tends to reduce blood pressure by vasodilation. ${ }^{27}$ However, because the hypoxic vascular effect is detected only in very severe hypoxia, the hypoxia produced in this study may have been insufficient to induce a local vascular effect.

The blood pressure response to intermittent hypoxia while awake suggests that non-hypoxic factors may play an important part in raising blood pressure during apnoeic episodes. In this regard, the improvement of desaturation may be insufficient to prevent hypertension-related complications in patients with OSA.

The authors thank $\mathrm{Dr} J$ Midorikawa for valuable technical assistance and $\mathrm{Mr} \mathrm{B}$ Bell for reading the manuscript.

1 Guilleminault C, Tilkian A, Dement WC. The sleep apnea syndromes. Ann Rev Med 1976;27:465-84.

2 Tilkian AG, Guilleminault C, Schroeder JS, Lehrman KL, Simmons FB, Dement WC. Hemodynamics in sleepinduced apnea: studies during wakefulness and sleep. Ann induced apnea: studies during

3 Schroeder JS, Motta J, Guilleminault C. Hemodynamic studies in sleep apnea. In: Guilleminault C, Dement WC, eds. Sleep apnea syndromes. New York: Alan R. Liss, 1978; 177-96.

4 Scharf SM. Influence of sleep state and breathing on cardiovascular function. In: Saunders NA, Sullivan CE, eds. Sleep and breathing. New York: Dekker, 1984;221-40.

5 Shepard JW Jr. Gas exchange and hemodynamics during sleep. Med Clin North Am 1985;69:1243-64.

6 Shepard JW Jr. Hemodynamics in obstructive sleep apnea. In: Fletcher EC, eds. Abnormalities of respiration during sleep. Orlando: Grune and Stratton, 1986;39-61.

7 Watanabe T, Mano T, Iwase S, Sugiyama Y, Okada $H$, Takeuchi S, et al. Enhanced muscle sympathetic nerve activity during sleep apnea in the elderly. $\mathcal{F}$ Auton Nerv Syst 1992;37:223-6.

8 Iwase N, Kikuchi Y, Hida W, Miki H, Taguchi O, Satoh $\mathrm{M}$, et al. Effects of repetitive airway obstruction on $\mathrm{O}_{2}$ $\mathrm{M}$, et at. Efration and systemic and pulmonary arterial pulmonary arterial pressure in anaesthetized dogs. Am Rev Respir Dis arterial pressure in

9 Hedner JA, Wilcox I, Laks L, Grunstein RR, Sullivan CE. A specific and potent pressor effect of hypoxia in patients with sleep apnea. Am Rev Respir Dis 1992;146:1240-5.

10 Aardweg JG van den, Karemaker JM. Repetitive apneas induce periodic hypertension in normal subjects through hypoxia. F Appl Physiol 1992;72:821-7.

11 Fletcher EC, Lesske J, Behm R, Miller CC, Stauss H, Unger T. Carotid chemoreceptors, systemic blood pressure, and chronic episodic hypoxia mimicking sleep apnea. $\mathcal{F}$ Appl Physiol 1992;72:1978-84

12 Fletcher EC, Lesske J, Qian W, Miller CC, Unger T. Repetitive, episodic hypoxia causes diurnal elevation of blood pressure in rats. Hypertension 1992;19:555-61.

13 Parish JM, Shepard JW. Cardiovascular effects of sleep disorders. Chest 1990;97:1220-6. 
14 Garpestad E, Katayama H, Parker JA, Ringler J, Lilly J, Yasuda T, et al. Stroke volume and cardiac output decrease at termination of obstructive apneas. $\mathcal{F}$ Appl Physiol 1992; 73:1743-8.

15 Tolle FA, Judy WV, Yu P, Markland ON. Reduced stroke volume related to pleural pressure in obstructive sleep apnea. F Appl Physiol 1983;55:1718-24.

16 Richardson DW, Wasserman AJ, Patterson JL Jr. General and regional circulatory responses to change in blood $\mathrm{pH}$ and carbon dioxide tension. $\mathcal{F}$ Clin Invest 1961;40:31-43.

17 Ringler J, Basner RC, Shannon R, Schwartzstein R, Manning $\mathrm{H}$, Weinberger $\mathrm{SE}$, et al. Hypoxemia alone does not explain blood pressure elevations after obstructive apneas. I Appl Physiol 1990;69:2143-8.

18 Davies RJO, Belt PJ, Roberts SJ, Ali NJ, Stradling JR Arterial blood pressure responses to graded transien arousal from sleep in normal humans. $\mathcal{F}$ Appl Physiol 1993; 74:1123-30.

19 Satoh M, Hida W, Chonan T, Miki H, Iwase N, Taguchi $\mathrm{O}$, et al. Role of hypoxic drive in regulation of postapneic ventilation during sleep in patients with obstructive sleep apnea. Am Rev Respir Dis 1991;143:481-5.

20 Rechtschaffen A, Kakes A. A manual of standardized terminology, techniques and scoring system for sleep stages of human subjects. Washington DC: National Institute of Health, Publication No. 204, 1968

21 Parati G, Gasadei R, Groppelli A, DiRienzo M, Mancia G. Comparison of finger and intra-arterial blood pressure monitoring at rest and during laboratory testing. Hypertension 1989;13:647-55.

22 Daly MdeB, Scott MJ. The cardiovascular responses to stimulation of the carotid body chemoreceptors in the dog. 7 Physiol (Lond) 1963;165:179-97. (Lond) 1963,165:179-97.

(he cardiovascular response to alveolar hypoxia in lambs. $f$

24 Kontos HA, Vetrovec GW, Richardson DW. Role of carotid chemoreceptors in circulatory response to hypoxia in dogs. f Appl Physiol 1970;28:561-5.

25 Vatner SF, Rutherford JD. Control of the myocardial contractile state by carotid chemo- and baroreceptor and pulmonary inflation reflexes in conscious dogs. $f$ Clin Invest 1978;61:1593-601.

26 Lugliani R, Whipp BJ, Wasserman K. A role for the carotid body in cardiovascular control in man. Chest 1973;63. body in 50 .

27 Daugherty RM Jr, Scott JB, Dabney JM, Haddy FJ. Local effects of $\mathrm{O}_{2}$ and $\mathrm{CO}_{2}$ on limb, renal and coronary vascular resistances. Am f Physiol 1967;213:1102-10. 